\title{
Simulation Service System with Cloud Manufacturing for Industrial Robot
}

\author{
Junhao Pan ${ }^{1, ~ a, ~ Y o n g ~ Z h u o, ~ b, ~ S h e n g h u i ~ L i a o ~}{ }^{1, c}$, Liang Hou ${ }^{1, d}$ \\ ${ }^{1}$ School of Aerospace Engineering, Xiamen University, Xiamen, 361005, China \\ aemail: leopanjh@hotmail.com, bemail: zhuoyong@xmu.edu.cn, \\ cemail: 2286866105@qq.com, ${ }^{d}$ email: hliang@xmu.edu.cn.
}

\begin{abstract}
Keywords: industrial robot, simulation, Cloud Manufacturing.
Abstract. As digital information technology is continuously developing and the application of Internet is much wider, the function of simulation system for industrial robot is no longer limited to single simulation. With the introduction of emerging technologies, especially Cloud Manufacturing, the integration service requirement for industrial robot simulation system is put up. Based on Virtual Reality and Cloud Manufacturing, a simulation service system prototype is designed with cloud manufacturing for industrial robot. The system is deployed on a cloud server with B/S architecture and can be accessed by a browser. And the system includes robot information service module and robot simulation service module. Robot information service module provides robot information retrieving, robot welding process recommendation and other services. And robot simulation service module can provide a variety of processing simulation, like robot welding, robot grinding, robot cutting and so on. The system developed in this paper has a certain practicality, and can be effectively used in production, teaching and other occasions.
\end{abstract}

\section{Introduction}

Robot technology is one of key technologies in the field of intelligent manufacturing, and its development level greatly reflects the level of intelligent manufacturing. Industrial robot is industrial-oriented robot, and generally is multi-joint manipulator or multi-degree-of-freedom machine, which integrate a variety of technologies, like mechanism, electronics, control and so on[1-2]. And industrial robot not only can be manipulated by users, but also can execute pre-set program. With the continuous improvement of industrial information technology, industrial robot plays an more important role in automated production. And robot simulation, an effective tool for robot performance and working characteristics, occupies an important position in the field of robot research and provides references for manufacturing.

Cloud Manufacturing is the product of manufacturing industry combined with cloud computing, which first proposed by Chinese Ministry of Science and Technology in 2010. At present, there is not yet a unified definition for Cloud Manufacturing, and generally agreed the definition that is put forward by academician from the Chinese Academy of Engineering Li Baihu, "Cloud manufacturing is a service-oriented, efficient and low cost of networking and knowledge-based new model of intelligent manufacturing"[3-4]. Since the concept of Cloud Manufacturing is proposed, Chinese scholars has been vigorously promoted in the international academia, and foreign academia is gradually getting interested in Cloud Manufacturing. Compared with the foreign researches, Chinese researchers has made a lot of theoretical research and application of Cloud Manufacturing[5-6]. After seven years of development, the researches of theory and application is becoming more and more, and Cloud Manufacturing will be an important research area in future.

In this paper, a simulation service system is built up for industrial robot based on Virtual Reality and Cloud Manufacturing. The system can provide robot simulation with high sense of reality and multi-directional resource sharing, which will be the future development direction of the robot simulation system. The primary exploration of system is dicussed in this paper, and robot simulation, robot information query and robot welding process recommendation are integrated in the system. 


\section{Framework of System}

The system is built by $\mathrm{B} / \mathrm{S}$ architecture (Browser/Server mode). And the web browser is the main application software and the core part of system is deployed on the server. The system of this paper is divided into two levels: the server and the client. Different from the traditional $\mathrm{B} / \mathrm{S}$ mode, the system is deployed on the cloud server, with the use of powerful computing power and resource integration capability of cloud server, to further improve system performance. Meanwhile, client deployed in the browser can effectively access to system to reduce the inconvenience of local operations. The framework of the system is shown in Fig.1(a), and Fig.1(b) is the home page of the system.

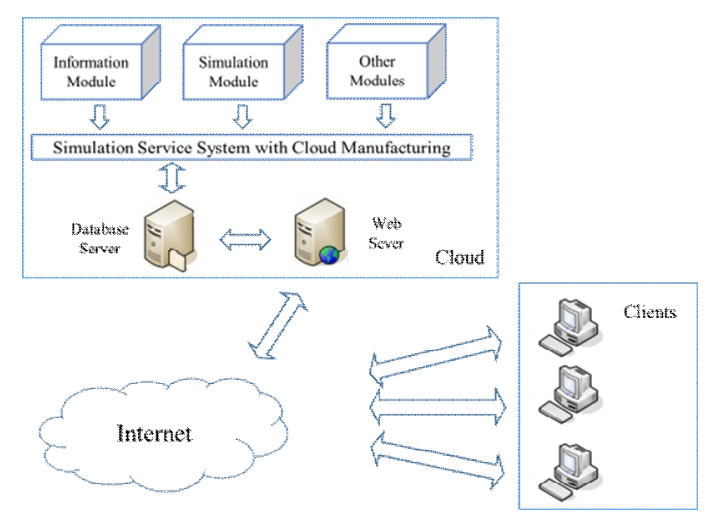

(a)

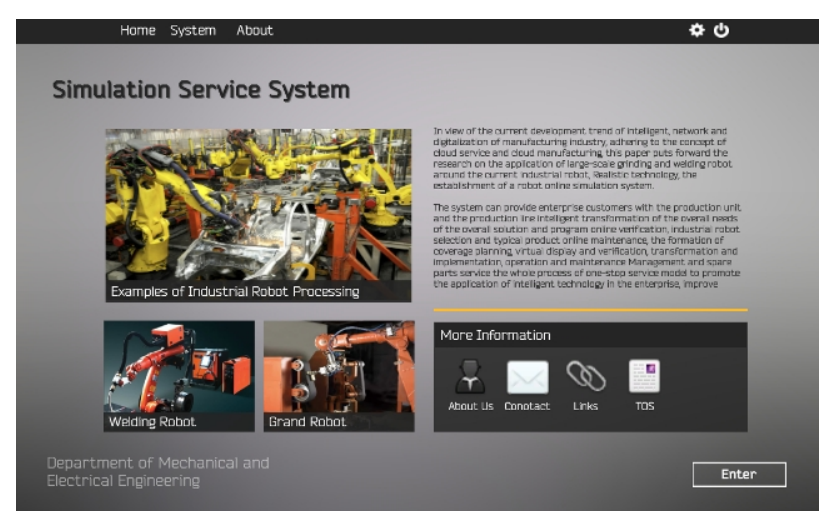

(b)

Fig.1 Framework of system(a) and home page of the system(b)

\section{Information Service Module}

The information module is designed for robot information query and robot welding process recommendation, which can provide robot information retrieval, robot online selection and automatically generating recommended industrial robot welding process parameters. There are two databases in the information module, robot information database and robot welding process database.

There are ten tables in robot information database, and the specific database tables are connected as shown in Fig.2(a), and the main page of robot information module is shown in Fig.2(b).

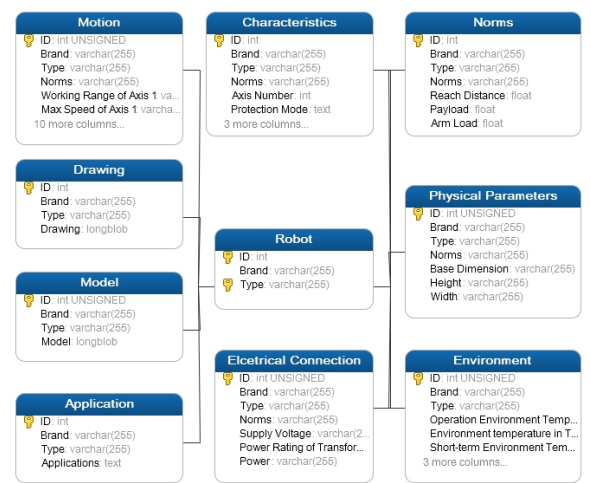

(a)

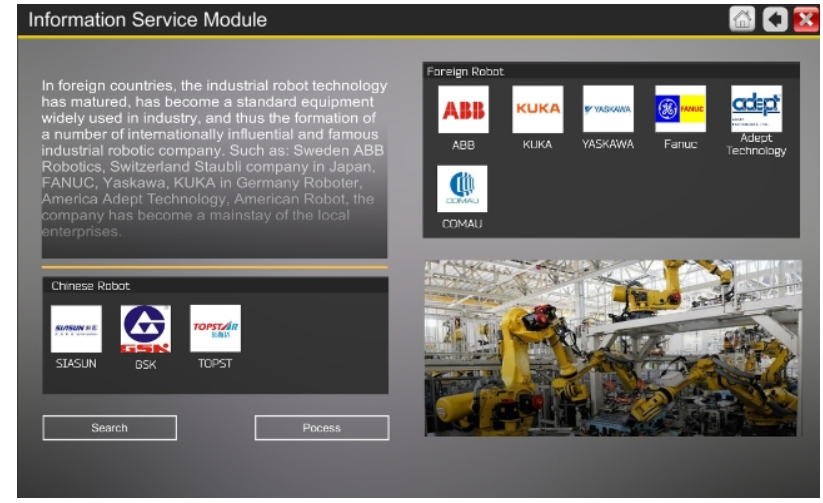

(b)

Fig. 2 Tables of robot information database(a) and main page(b)

Robot welding is widely used in the manufacturing, chemical and other fields. The traditional design method of welding process is complicated, which not noly need designers to read many design manuals, but also need design experience. So there high quality requirements for designers and the design period of development is too long. With the development of computer technology, there is a new method to design welding process by computer. In this paper, the robot welding process database is bulit and an expert system for robot welding process is established. 
In robot welding process, there are many parameters, such as base brand, base thickness, wire diameter, welding current, wire length and so on. In this paper, the knowledge base of steel welding is established, and the knowledge base of robot welding technology is established according to the collected expert knowledge, including the base knowledge base, the welding material knowledge base, the joint knowledge base and the process parameter knowledge base. The contents and the relationship between each bases are shown in Fig.3(a).

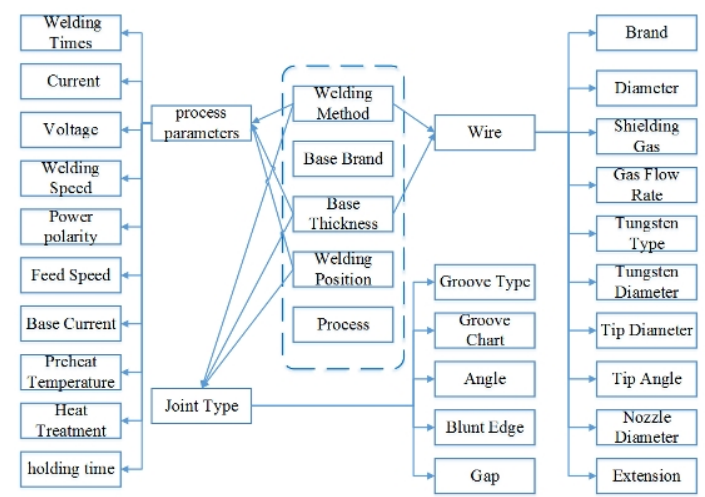

(a)

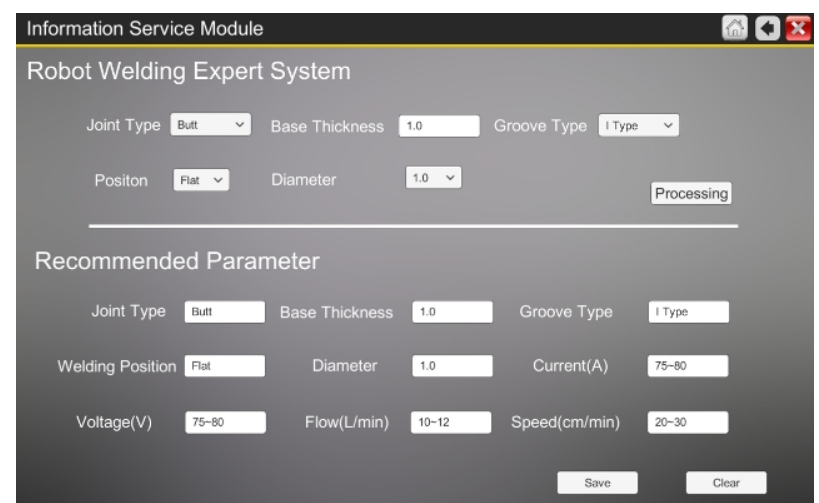

(b)

Fig.3 Bases relationship(a), main page of robot welding expert system(b)

According to the entered information and existing knowledge and case, new knowledge and case mechanism are reasoned out. In this paper, the expert system of robot welding process is established in information service module and the main page is shown in Fig.3(b). By forward reasoning, reasoning is divided into three steps:

1) initial inputs: initial formation, like base brand, base thickness, welding position and so on, is input by users;

2) intermediate results: the final results is interfered by users, through modifying parameters to improve the accuracy;

3) final results: according to the initial input and the intermediate results, the final results are reasoned, which is recommended welding parameters.

\section{Simulation Service Module}

The simulation service module of this paper is developed in Unity3d engine with Virtual Reality, which contains a few of functions, like robot simulation, robot case display, robot teaching, robot scene roaming and so on.

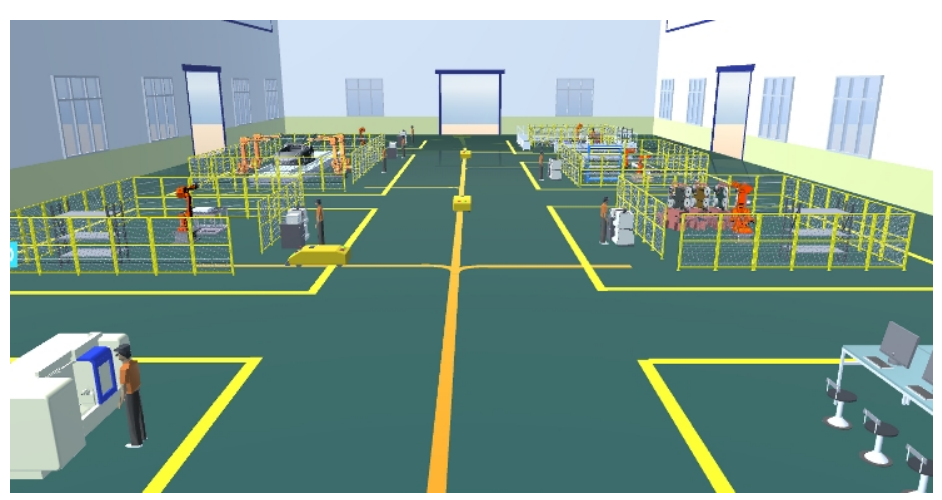

(a)

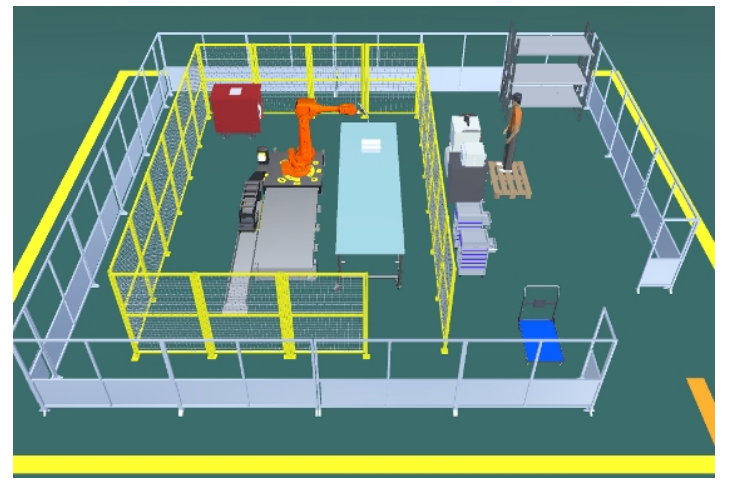

(b)

Fig.4 Scene of system(a) and virtual robot welding workshop(b)

A number of scenes is integrated in a large scene. By switching the camera, scene change can be achieved. The scene of system is shown in Fig.4(a). According to real factory layout, the scene is 
optimized on the basis of the required functions. And there are many virtual robot workshops in the system secen, like robot welding workshop, robot grinding workshop, robot palletizing workshop, robot spot welding workshop and so on.

The robot welding is introduced as an example, and the virtual robot welding workshop is shown in Fig.4(b). According to user need, the appropriate welding parameters can be set, such as welding speed, working angle, tilt angle and so on. There are many typical welding types, such as plate welding, tube-plate welding and pipe welding. By clicking the "Feature Extraction" button, features of model can be chosen as weld for welding simulation. Besides, the program of slimulation can be output as a Text file. Figure 6-15 shows an example of a welding simulation of a spline weld. Like welding simulation, there are a few of robot slimulations can be achieved.

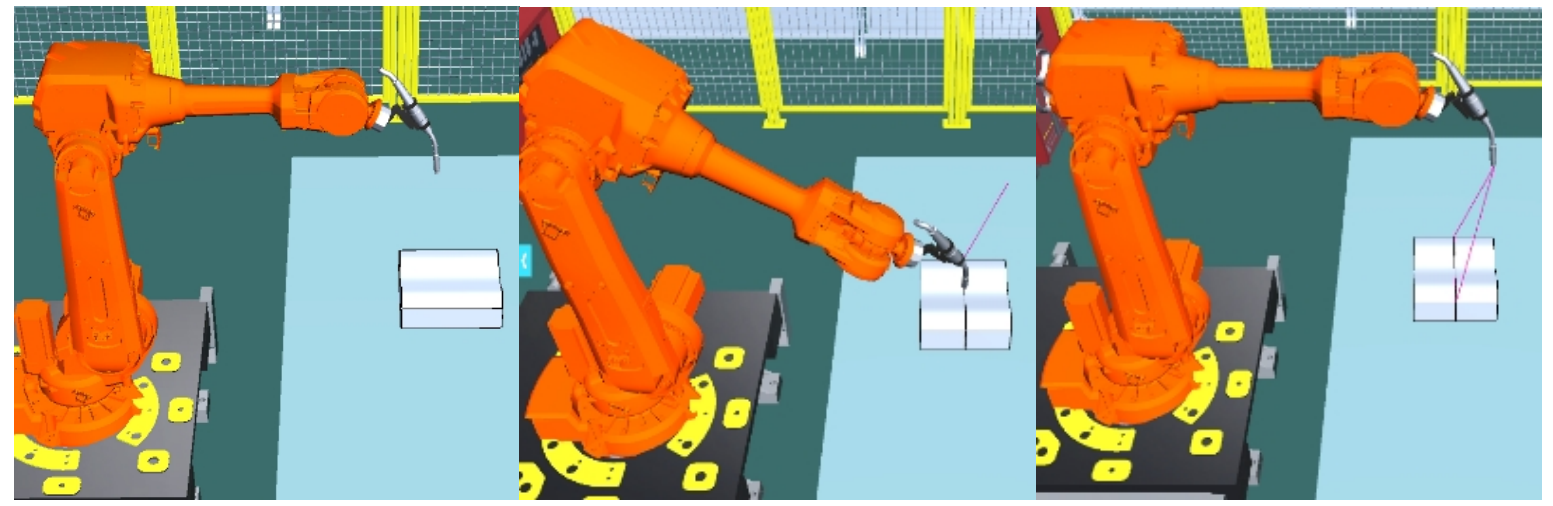

Fig.5 Example of welding simulation

\section{Conclusions}

To meet the developing need of industrial robot simulation system, a prototype of simulation service system for industrial robots is developed in this paper with Virtual Reality and Cloud Manufacturing. The system can be used in robot information service, robot simulation service and so on. After test, the system has a certain degree of integration, and can be effectively used for teaching, production and other occasions.

\section{Acknowledgements}

This work is supported by the Science and Technology Major Project of Fujian Province, China (2015HZ0002-1) and Collaborative Innovation Center of High-End Equipment Manufacturing in Fujian.

\section{References}

[1] J J Craig: Introduction to Robotics: Mechanics and Control (Pearson Education, Inc, 1986).

[2] B Siciliano et al: Advanced Textbooks in Control \& Signal Processing, 2009, 4(12), 76-85.

[3] B H Li, et al: Computer Integrated Manufacturing Systems, 2010, 16(1):1-7+16. (In Chinese)

[4] X Xu: Robotics and Computer-Integrated Manufacturing, 2012, 28(1):75-86.

[5] D Wu, M J Greer, D W Rosen and Schaefer D: Journal of Manufacturing Systems, 2013, 32(4):564-579.

[6] W X Vincent, X W Xu: Robotics and Computer-Integrated Manufacturing, 2013, 29(4):232-247. 